\title{
Vertentes do realismo na literatura brasileira contemporânea
}

\author{
Ana Cristina Coutinho Viegas \\ Universidade Estadual do Rio de Janeiro
}

\begin{abstract}
RESUMO: AS FRONTEIRAS ENTRE REALIDADE E FICÇÃO VÊM ADQUIRINDO NOVOS CONTORNOS. A PARTIR DE TEXTOS DE FERRÉZ, MARÇAL AQUINO E MODESTO CARONE, PROPÕE-SE A DISCUSSÃO DE RELAÇÕES ENTRE OS PACTOS MIMÉTICOS CONSTRUÍDOS NA MÍDIA ELETRÔNICA E O DESNUDAMENTO E A CONSEQÜENTE NEGAÇÃO DESSES PACTOS NA LITERATURA CONTEMPORÂNEA COMO UMA FORMA DE RESISTÊNCIA.
\end{abstract}

ABSTRACT: THE BOUNDARIES BETWEEN REALITY AND FICTION HAVE BEEN RECEIVING NEW CONTOURS. BASED ON TEXTS BY FERRÉZ, MARÇAL AQUINO AND MODESTO CARONE, IT IS PROPOSED HERE THE DISCUSSION OF MIMETIC PACTS BUILT IN THE ELECTRONIC MEDIA, ITS REVELATION AND ITS CONSEQUENT DENIAL IN THE CONTEMPORARY LITERATURE AS A WAY OF RESISTANCE.

PALAVRAS-CHAVE: LITERATURA CONTEMPORÂNEA - MÍDIA ELETRÔNICA - MÍMESIS - RESISTEENCIA

KEY-WORDS: CONTEMPORARY LITERATURE - ELECTRONIC MEDIA - MÍMESIS - RESISTANCE 
esde Aristóteles, discutem-se, no mundo ocidental, as diferenças entre ficção e realidade. Em sua Arte poética, guiado por preocupações estéticas, o filósofo grego já apontava distinções entre o prazer decorrente da mímesis e o que se experimenta na relação com o mundo empírico.

Ao longo do século XX, correntes críticas se revezaram entre a valorização do estudo das relações entre o texto literário e o real e o destaque para as combinações lingüísticas operadas no próprio texto (close reading). Com os estudos culturais e o avanço das novas tecnologias, o caminho a ser trilhado pela teoria literária tornou-se mais complexo, com a necessidade não apenas de se rever o corpus que constitui seu objeto de estudo, mas também de se refletir sobre os métodos e pressupostos que orientam esse estudo.

No mundo atual, o debate em torno de ficção e realidade vem assumindo novos contornos, especialmente devido à expansão das mídias audiovisuais. Em meio a esse debate, entrou em cena o discurso das minorias, ou melhor, o esforço de promover a divulgação e o estudo das produções culturais de grupos marginalizados, como, por exemplo, os habitantes das favelas das grandes cidades brasileiras.

No Brasil, desde os anos 1970, pelo menos, foram-se criando subconjuntos literários diferentes na temática, mas semelhantes quanto à retomada de uma "concepção hipermimética da escrita", que vem tomando fôlego na cultura contemporânea. Uma análise da produção televisiva, cinematográfica, fonográfica e editorial revela uma presença maior de situações e personagens de nossas periferias. Dentro dessa perspectiva, de acordo com Alfredo Bosi, a interpretação literária e a crítica estética são substituídas pela valorização do assunto. Em outro extremo, observa-se a produção de uma "literatura hipermediadora", isto é, uma escrita feita de pastiche, paródia, colagem, enfim, uma escrita de citação (BOSI: 2002: 251).

Um dos caminhos trilhados pela literatura brasileira vem a ser justamente o de reforçar o seu caráter ficcional. Em oposição às práticas miméticas que caracterizam as narrativas construídas pela mídia eletrônica, livros como Eu receberia as piores notícias dos seus lindos lábios, de Marçal Aquino (AQUINO, 2005), lembram ao leitor, a todo instante, o pacto ficcional. Trata-se de obras que, a partir do tema ou do enredo que o narrador resolveu escolher como suporte, se realizam muito mais especificamente como artefatos literários. Enquanto, por exemplo, o telejornalismo se utiliza de elementos como a imagem - veiculada como prova 
irrefutável -, pesquisas de opinião, estatísticas, para se colocar como porta-voz da "verdade" dos fatos, no texto literário os dados da realidade imediata são deslocados para um contexto em que se estimula a realização do imaginário. Como o texto ficcional contém elementos do real sem que se esgote na descrição desse real, o seu componente fictício não tem o caráter de uma finalidade em si mesma, mas é, enquanto fingido, a preparação de um imaginário (ISER, 1996: 13).

Além disso, o discurso da mídia tenta passar uma idéia de verdade objetiva e, com isso, tende a naturalizar construções discursivas. O texto literário, por sua vez, revela o caráter de linguagem inerente aos outros campos discursivos.

Em Tempo presente: notas sobre a mudança de uma cultura, Beatriz Sarlo, ressaltando uma perspectiva político-cultural, afirma que uma esquerda é, por definição, antimimética, ou seja, precisa afastar-se de todas as práticas miméticas que hoje caracterizam a política: as pesquisas, a construção de uma opinião pública que reproduz as condições existentes, os medos sociais, a aquiescência automática diante das relações de poder estabelecidas. Ser hoje de esquerda é, segundo a autora, intervir no espaço público e na política; é refutar os pactos miméticos (SARLO, 2005: 236).

Não é só no telejornalismo que se assiste a tal procedimento de construção de realidades. Os mesmos "pactos miméticos" a que se refere Beatriz Sarlo são adotados pela mídia para disseminar "realidades" não só do universo da política stricto sensu, mas também sociais e culturais. Ao analisar, por exemplo, as séries brasileiras produzidas para a televisão, observa-se um interesse especial por obras que possibilitem a discussão de temas de caráter nacionalista.

O discurso midiático tem como um de seus objetivos reduzir as incertezas das contingências do mundo e, para isso, trabalha com a redundância. A literatura, na contramão desse processo, ao recombinar elementos de ordem lingüística, social, emocional, etc., realiza uma transgressão de limites e novos significados vêm à tona.

O narrador de Eu receberia as piores noticias dos seus lindos lábios não quer que seu leitor perca de vista a perspectiva de que o "real" se constitui numa construção de linguagem. Num jogo que mostra a todo instante que "isso não é um cachimbo", dá-se a incorporação crítica de elementos não só do jornalis-

1 Referência ao texto Isto não é um cachimbo, de Foucault, no qual, a partir de quadro de René Magritte, o filósofo reflete sobre as relações entre arte e realidade (FOUCAULT, 1990). 
mo, como também da linguagem cinematográfica. Vale lembrar que o autor, Marçal Aquino, é um escritor com experiência de roteirista de cinema.

A narrativa se passa numa cidade do Pará, a qual tem no garimpo sua principal atividade econômica. Em ambiente hostil a qualquer manifestação de delicadeza, o fotógrafo Cauby, narrador-protagonista homônimo de um cantor bastante conhecido do grande público, se envolve numa história de amor com Lavínia, mulher do pastor. Tendo como pano de fundo um clima de guerra entre a mineradora e seus adversários, a narrativa dessa história de amor clandestino segue entrecortada por outras histórias, como a do careca que vive na mesma pensão do protagonista e conta sua paixão platônica para um menino que grava os depoimentos a fim de escrever um livro a partir deles. Em cenário povoado de silêncios, entrechocam-se várias versões que não se confirmam, como a de que a mineradora havia contratado indivíduos da Paraíba para exterminar o pessoal do sindicato. Havia "uma atmosfera de ameaça", tensão demais entre os garimpeiros e a mineradora. "Um clima de guerra, de acerto de contas [...] Faltava apenas alguém acender o pavio" (AQUINO, 2005: 190). Tudo isso pontuado por referências constantes a trechos do livro $O$ que vemos no mundo - um tratado sobre o amor humano, escrito pelo pseudofilósofo Benjamin Schianberg.

Apesar de o título do livro acenar com a promessa de um caso de amor cor-derosa nos moldes das telenovelas ou de filmes hollywoodianos, o narrador percorre um território avesso a estereótipos, e o romance se abre com uma provocação ao leitor: "Não adianta explicar. Você não vai entender" (AQUINO, 2005: 11).

Cauby já havia trabalhado em reportagem policial em São Paulo. Fotógrafo profissional, chega à cidade para produzir um livro financiado por uma agência francesa interessada nos conflitos do garimpo no Brasil. Um dos personagens que vão fazer parte da nova vida de Cauby é o responsável pelo jornal local - um semanário financiado pela mineradora que só publica notícias que interessam aos patrões. Conhecido pelo pseudônimo de Viktor Laurence, o jornalista não permite que as pessoas conheçam seu verdadeiro nome. Na verdade, a questão do nome está ligada ao fato de, ao longo de toda a narrativa, os personagens irem trocando de máscaras e compondo novas identidades. O próprio Cauby é um elemento de fora da cidade que vem para começar uma vida nova. Sua amada, Lavínia, no final, internada numa clínica para tratamento psiquiátrico, não se lembra de seu passado e passa a ser identificada como Lúcia. 
A narrativa atinge seu clímax quando, suspeito de ser o responsável pela morte do pastor, Cauby é linchado por um grupo de moradores e fica cego do olho direito. Após deixar o hospital, retorna à sua atividade de fotógrafo. Denominando-se "um Lázaro de tempos multimídia", ressalta que "tudo parece desfocado à sua volta” (AQUINO, 2005: 213).

Além disso, explode a tensão entre mineradores e garimpeiros: "[...] Naquela tarde, enquanto um bando de devotos da Igreja me apedrejava num terreno baldio nos arrabaldes da cidade, num acampamento no meio do mato eram encontrados os corpos de cinco garimpeiros que andavam sumidos. Tinham sido chacinados. Os parentes e amigos trouxeram os cadáveres para a cidade, exibiram em praça pública. O fedor de decomposição empesteou tudo e perfumou a revolta geral. Houve ataques contra a mineradora, que reagiu com sua matilha de jagunços em confrontos que, é óbvio, dada a disparidade de armamento e, digamos, de know-how dos envolvidos, só deixaram baixas nas fileiras da comunidade. Isso aumentou ainda mais o ódio. Os ataques contra a mineradora recomeçaram e vararam a madrugada. Puseram fogo numa draga. E depois no escritório e nos alojamentos da empresa" (AQUINO, 2005: 213).

Durante o episódio, a casa de Cauby é incendiada. Não se sabe exatamente o motivo, já que houve "gente aproveitando a temperatura da hora para dirimir rixas antigas" (AQUINO, 2005: 214).

No incêndio, todo o material preparado pelo narrador-protagonista para a revista francesa é destruído. Sem nenhuma versão privilegiada para se publicar sobre os acontecimentos, o narrador se diz pronto para, mais uma vez, "recomeçar da estaca zero" (AQUINO, 2005: 217). Não se chega ao conhecimento e ao registro de uma verdade. Frustrando as expectativas daquele leitor interessado em saber "o que realmente aconteceu", o romance se fecha, conferindo ao ato de narrar a tarefa de se realizar como recombinação de textos que compõem uma versão verossímil em aberto. Além disso, narrativas como a de Marçal Aquino põem em relevo a incapacidade de um texto ficcional "contar a verdade"2.

2 "[...] a ficção é incapaz de contar a verdade [...] Romancistas e contistas são como o menino que brincava de gritar por socorro: estão condenados a ser perpetuamente desacreditados. Você poderia pôr a declaração numa nota de rodapé e assiná-la com suas iniciais e a data, mas isso não a faria passar da ficção para o fato. O subtítulo 'Um romance' é suficiente para garantir isso [...] Mesmo que um romance traga fatos concretos, não se torna, de alguma forma, mais verdadeiro. Novamente, o fato de sabermos ser isso um romance garante que não examinemos tais declarações pelo seu valor de verdade [...]” ( EAGLETON, 2005: 130). 
No pólo da produção que recupera o caráter hipermimético da escrita, encontra-se Capão pecado, romance de Ferréz que fala sobre uma favela paulista, o Capão Redondo, "um lugar por Deus abandonado e pelo diabo batizado" (FERRÉZ, 2005).

Ao ler os textos de Ferréz, especialmente seu prefácio para o livro Literatura marginal: talentos da escrita (FERRÉZ, 2005) intitulado "Terrorismo literário", é inevitável observar o deslocamento da palavra " marginal", que, em nossa literatura, constituiu adjetivo forte para caracterizar a geração politicamente engajada dos anos 1970.

Uma leitura comparativa do prefácio de Ferréz com o ensaio "Malditos marginais hereges", de Ana Cristina Cesar, publicado em 1977, mostra pontos convergentes e divergentes no que se refere ao termo "marginal" (CESAR, 1993).

Nos anos 1970, "a intenção é construir a identidade do escritor com o povo a partir da própria vida do escritor (ou de dados bem selecionados dessa vida). De um escritor que, supostamente, não é consagrado". Esse escritor é "como o povo" e produzirá uma "literatura de solidariedade" (CESAR, 1993: 111).

Em ensaio publicado em livro dos anos 1980, ao tratar da produção literária dos anos 1960 e 1970, Antonio Candido também destaca o esforço dos escritores para apagar as distâncias sociais e identificar-se com a matéria popular. $\mathrm{O}$ uso da primeira pessoa constitui o recurso para unir autor e personagem (CANDIDO, 1987). É o caso, por exemplo, de vários contos de Rubem Fonseca, como "O cobrador", publicado em 1979.

No cenário atual, mudou-se o foco, já que, nas palavras de Ferréz, a periferia deixou de ser "retrato" e passou a tirar ela mesma a sua foto. Em vez de objeto da escrita, o excluído se faz sujeito do processo simbólico. Em diálogo com a geração 70, o autor afirma que "o mimeógrafo foi útil, mas a guerra é maior agora", uma vez que "os meios de comunicação estão aí, com mais de $50 \%$ de anunciantes por edição, bancando a ilusão que você terá que ter em sua mente" (FERRÉZ, 2005: 12).

O mimeógrafo não cabe mais no mundo globalizado. Não se trata mais de construir a identidade do escritor com o povo a partir do fato, por exemplo, de ser "esnobado ou explorado pelas editoras" (CESAR, 1993: 111). É imprescindível abrir um espaço nesse circuito da elite econômica e intelectual. Tomar parte nas vitrines das grandes livrarias, como lembra uma das dedi- 
catórias do livro Capão pecado: "Querido sistema, você pode até não ler, mas tudo bem, pelo menos viu a capa".

Canclini, em seu livro Consumidores e cidadãos, já teceu considerações sobre os modos como as mudanças na maneira de consumir alteraram as possibilidades e formas de encarar a cidadania. Não se pode mais alinhar o consumo apenas ao mercado e a táticas publicitárias. Há uma coerência entre os lugares onde os membros de uma classe ou de uma fração de classe estudam, passam as férias e também naquilo que lêem - o que evidencia aspectos simbólicos e estéticos da "racionalidade consumidora" (CANCLINI, 1995). Em tempos de mercados transnacionais amparados pelo desenvolvimento da informática e de outros meios de comunicação eletrônicos, a cidadania passa cada vez mais pelo consumo. Além disso, o que não está nas telinhas simplesmente não existe.

Por outro lado, essa produção contemporânea se aproxima da geração marginal dos anos 1970 no que diz respeito a uma missão pedagógica do escritor, ou seja, sacudir, chocar o leitor e levá-lo a refletir sobre a massa dos "excluídos sociais".

Quanto a Ferréz, além da denúncia social, o autor também almeja o reconhecimento dessa produção como literatura, como arte: "[...] não somos uma literatura menor [...]" (FERRÉZ, 2005: 13). O romance, como gênero, pertence a um cânone que exclui a periferia. Essa exclusão se concretiza no acesso precário à leitura e à escrita, o que é tematizado pelo próprio autor em seu livro ${ }^{3}$. Entrecortado por textos de rap de grupos musicais como o Realismo Frontal, Capão pecado está em busca de uma linguagem literária própria.

A divisão apresentada por Alfredo Bosi para esboçar um quadro das manifestações literárias contemporâneas (2002) não é suficiente para abranger a diversidade de rumos tomados por essas obras. Resumo de Ana, de Modesto Carone, constitui uma terceira postura em relação ao "real", isto é, a força dessa narrativa não se encontra na atitude de desnudar o caráter ficcional do texto nem na apresentação bruta de uma realidade. O livro gira em torno da vida miúda de duas personagens - Ana Baldochi, avó do narrador, e Ciro, filho de Ana e tio do narrador (CARONE, 2002). Faz-se uma crítica ao

3 Sobre a questão da desigualdade no processo educacional brasileiro, encontram-se, em Capão pecado, passagens como: "O médico se formou na USP, um recinto que era para o povo, mas já foi reservado desde sua criação para os playboys” (FERRÉZ, 2005: 148). 
progresso pelo ângulo do trabalhador, ou seja, na contramão dos mitos da modernização paulista.

Guardadas as diferenças entre as duas propostas estéticas, pode-se dizer que tanto Modesto Carone quanto Ferréz optam por revelar uma outra São Paulo, ou seja, a periferia, os grupos sociais à margem do êxito do progresso econômico. Em Resumo de Ana, resgata-se a memória de pessoas comuns e anônimas. É como empregada doméstica que Ana trabalha em Sorocaba e depois em São Paulo, até se casar com Balila Baldochi, com o qual vem a ter três filhos. Da mãe para os filhos, transfere-se a herança do trabalho mal-remunerado nas casas das famílias abastadas, na fábrica ou no comércio.

No que diz respeito ao foco narrativo, Resumo de Ana constitui uma narrativa em terceira pessoa entrecortada por passagens em primeira pessoa nas quais o narrador participa das memórias de sua família. Esse narrador em primeira pessoa apresenta traços em comum com o autor. A biografia de Carone, nascido em Sorocaba na década de 1930, leva o leitor a estabelecer uma possível relação entre o narrador e o próprio autor.

Ao tecer considerações sobre um "novo realismo" na literatura, o professor Karl Erik Schollhammer considera que "os relatos autobiográficos em primeira pessoa, a inclusão de protagonistas reais, o uso de nomes próprios reais e a inserção de fotos e desenhos são elementos de desconstrução da estrutura narrativa tradicional do romance" e "criam uma espécie de realismo textual que desequilibra a relação entre ficção e documento”. A partir dessa observação, certas narrativas contemporâneas brasileiras "podem ser entendidas como encenações ou instalações performáticas das arbitrariedades do 'eu' autoral' (SCHOLLHAMMER, 2006: 3).

O conceito de "performativo" passou a fazer parte dos estudos literários nos anos 1950, quando o lingüista Austin empregou o termo para definir um ato de fala que realiza a ação à qual parece se referir. Tempos depois, o termo "performance" ganhou relevância nos estudos de outros teóricos, como Wolfgang Iser, incomodados com a inadequação do termo "representação" para explicar o que ocorre nas artes e na literatura (SCHOLLHAMMER, 2006: 4).

Nota-se, em muitos escritores contemporâneos, a urgência em relacionar a literatura com os problemas sociais da exclusão e da violência. Ainda de acordo com Karl Erik, "entre o índice que traz para dentro da escrita a marca da realidade como evidência e testemunho e a performance que converte a 
recepção em intervenção poética sobre o mundo, a procura da literatura é dos efeitos e afetos que marcam as interseções dos nossos corpos na realidade da qual todos somos parte" (SCHOLLHAMMER, 2006: 5).

$\mathrm{O}$ esforço de incluir a realidade na escrita não deve, portanto, ser entendido numa perspectiva documental. Recursos lingüísticos como a redução radical do descritivo aliada a uma sintaxe enxuta e direta em Resumo de Ana ou a opção pela oralidade em Capão pecado constituem tentativas de se alcançar o impacto da palavra literária. Como ressalta o próprio Ferréz, "somos marginais mas antes somos literatura" (FERRÉZ, 2005: 13).

Exercendo uma função primordial da arte, os textos aqui estudados colocam o leitor diante das ambigüidades não apenas dos discursos, mas também da vida. Levar à descoberta de que as coisas podem acontecer de uma maneira diferente constitui uma forma de resistir.

Quanto à teoria, em vez de apresentar respostas, faz um convite para mais reflexão sobre os caminhos desse realismo contemporâneo.

\section{Referências Bibliográficas}

AQUINO, Marçal. Eu receberia as piores notícias dos seus lindos lábios. São Paulo: Companhia das Letras, 2005.

BOSI, Alfredo. Literatura e resistência. São Paulo: Companhia das Letras, 2002.

CANCLINI, Nestor García. Consumidores e cidadãos - conflitos multiculturais da globalização. Trad. Mauricio Santana Dias e Javier Rapp. Rio de Janeiro: Ed. UFRJ, 1995.

CANDIDO, Antonio. A nova narrativa. In: . A educação pela noite e outros ensaios. São Paulo: Ática, 1987.

CARONE, Modesto. Resumo de Ana. São Paulo: Companhia das Letras, 2002.

CESAR, Ana Cristina. Malditos marginais hereges. In: . Escritos no Rio. São Paulo: Brasiliense, 1993. p. 109-120.

EAGLETON, Terry. Depois da teoria - um olhar sobre os estudos culturais e o pós-modernismo. Trad. Maria Lucia Oliveira. Rio de Janeiro: Civilização Brasileira, 2005.

FERRÉZ. Capão pecado. Rio de Janeiro: Objetiva, 2005.

. Terrorismo literário. In: FERRÉZ (org.). Literatura marginal - talentos da escrita periférica. Rio de Janeiro: Agir, 2005. p. 9-16.

FOUCAULT, Michel. Isto não é um cachimbo. Trad. Jorge Coli. 2. ed. Rio de Janeiro: Paz e Terra, 1990. 
ISER, Wolfgang. O fictício e o imaginário - perspectivas de uma antropologia literária. Trad. Johannes Kretschmer. Rio de Janeiro: EdUERJ, 1996. . Os atos de fingir ou o que é fictício no texto ficcional. Trad. Heidrun Krieger Olinto e Luiz Costa Lima. In: LIMA, Luiz Costa. Teoria da literatura em suas fontes. 2. ed. Rio de Janeiro: Francisco Alves, 1983. v. 2, p. 384-416.

SARLO, Beatriz. Tempo presente: notas sobre a mudança de uma cultura. Trad. Luis Carlos Cabral. Rio de Janeiro: José Olympio, 2005.

SCHOLLHAMMER, Karl Erik. Do efeito ao afeto - os caminhos do realismo performático. In: XIV Seminário Internacional da Cátedra Padre Antonio Vieira de Estudos Portugueses, 2006, Rio de Janeiro. Texto inédito. PUC, 2006. 